Article

\title{
Conditions for a Meaningful Health Impact Assessment for Local Stakeholders: The Example of the Arve Valley in France
}

\author{
Mathilde Pascal *, Jean-Marc Yvon, Magali Corso, Myriam Blanchard, Perrine De Crouy-Chanel \\ and Sylvia Medina \\ Santé publique France, 12 rue du Val d'Osne, 94415 Saint Maurice, France; \\ Jean-Marc.YVON@santepubliquefrance.fr (J.-M.Y.); Magali.Corso@santepubliquefrance.fr (M.C.); \\ Myriam.Blanchard@santepubliquefrance.fr (M.B.); Perrine.DECROUY-CHANEL@santepubliquefrance.fr (P.D.C.-C.); \\ Sylvia.Medina@santepubliquefrance.fr (S.M.) \\ * Correspondence: Mathilde.Pascal@santepubliquefrance.fr
}

Received: 11 May 2020; Accepted: 27 May 2020; Published: 29 May 2020

\begin{abstract}
This article illustrates how a health impact assessment (HIA) can be used to promote a collaborative discussion among stakeholders as part of a local action plan aimed at improving air quality. We performed a HIA of the mortality impacts of long-term exposure to fine particles $\mathrm{PM}_{2.5}$ in the Arve Valley in France. This narrow valley can experience high levels of pollution mostly during winter. However, local stakeholders expressed strong, contradictory opinions on the associated health impacts. Our HIA helped overcome existing silos and shifted the overriding question from "Is it true that air pollution kills people?" to "What can we do to improve air quality?" HIAs have proven to be an excellent decision-support tool in many contexts. In addition, they should continue to be useful provided that their scope, specific objectives, choices, calculation assumptions, and limitations are thoroughly explained to all stakeholders and made easily accessible.
\end{abstract}

Keywords: health impact assessment; mortality; fine particles; stakeholders involvement

\section{Introduction}

Chronic exposure to outdoor air pollution, and especially to fine particles, has been proven to favor the development of various diseases [1-6], leading to premature mortality [7-9]. Despite extensive scientific literature on the topic, disbelief of the reality of these health impacts by stakeholders may impair actions to improve air quality. Victims of air pollution are not directly identifiable, as long-term exposure to air pollutants is a risk factor for a wide range of chronic diseases (e.g., cardiovascular, respiratory, renal diseases, cancer, ... ), while short-term exposure exacerbates the symptoms of an equally wide range of health pre-existing conditions. In addition, for fine particles $\left(\mathrm{PM}_{10}\right.$ and $\left.\mathrm{PM}_{2.5}\right)$, the European (EU) air quality regulatory values are less strict than the World Health Organization's (WHO) recommended guideline values. For instance, in France, according to the EU regulation, $\mathrm{PM}_{2.5}$ annual mean concentration should not exceed $25 \mu \mathrm{g} / \mathrm{m}^{3}\left(20 \mu \mathrm{g} / \mathrm{m}^{3}\right.$ in 2020), while the WHO guideline value is $10 \mu \mathrm{g} / \mathrm{m}^{3}$. Epidemiological studies document health impacts even below this value [9]. Finally, policies tackling air pollution directly question people's lifestyles and habits (e.g., use of cars vs. alternative transport modes, use of woodstoves ... ), and can therefore have a low public acceptance.

All of these factors contribute to debates on air pollution impacts and solutions.

The health impact assessment (HIA) approach was developed to help decision-makers understand the public health burden of the environmental or social determinants of health. It has been largely used to assess the health impacts of air pollution, and evaluate the potential benefits of planned or implemented actions [10]. Here, we illustrate how an HIA helped to bring all stakeholders 
(local politicians, industrials, non-governmental organizations ... ) together in a common goal, the development of a local air quality policy in a French valley, in a context of high debate around air pollution.

The Arve Valley is located in the French Alps, in the vicinity of the Mont Blanc country. The bottom of the valley gathers more than 150,000 inhabitants, with a high population density (Figure 1). The western part of the valley concentrates a broad range of industrial activities in a small territory. The slopes of the valley are dedicated to agriculture, and toward the east to tourism. The Mont Blanc country is an iconic and popular natural environment famous for outdoor activities. In this area of the valley, natural spaces (i.e., places without human constructions) can represent up to $97 \%$ of the surface of the municipalities.

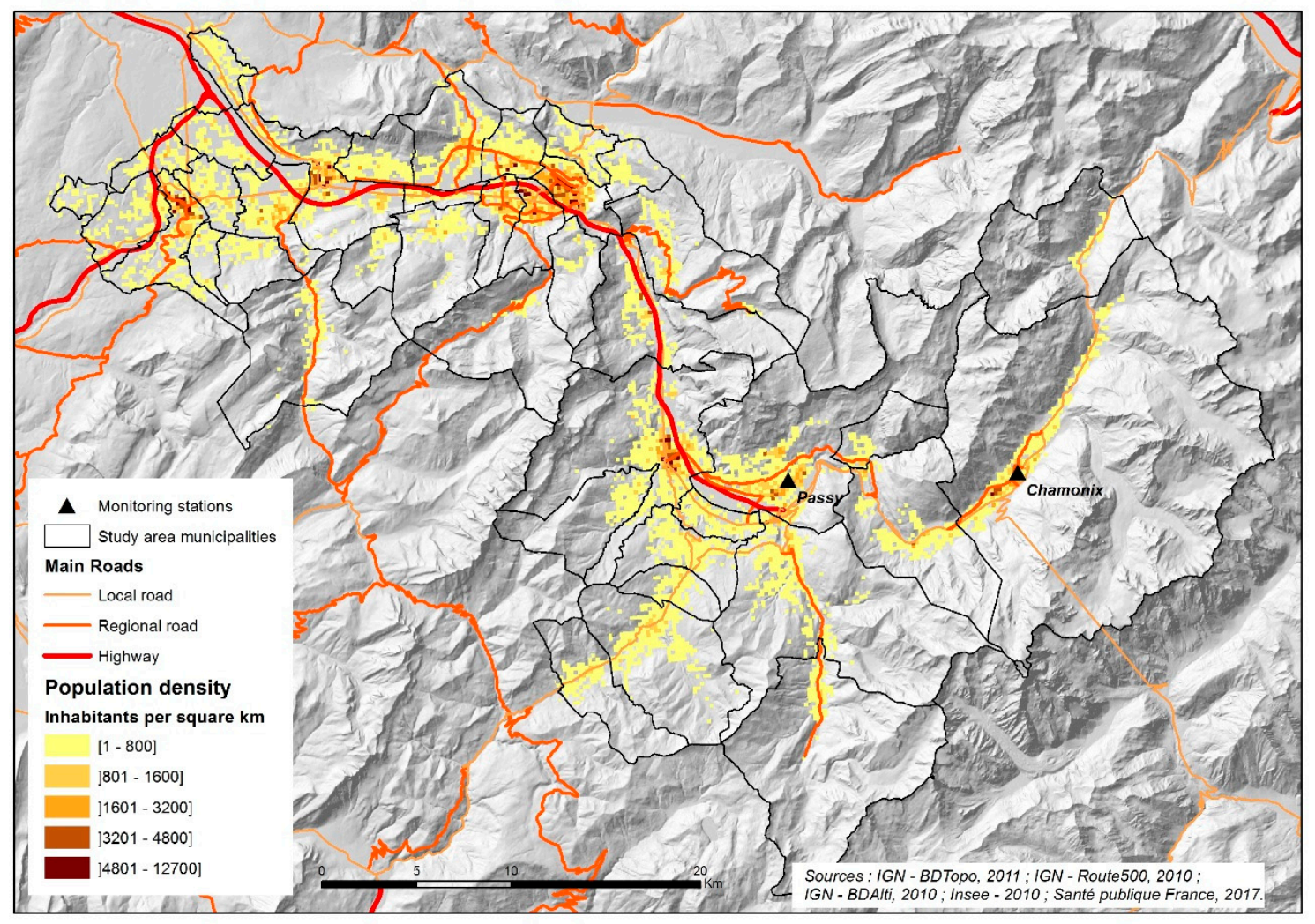

Figure 1. Population density in the Arve Valley (inhabitants per square km, 2012 census).

The valley is also the entry point of the tunnel under Mont Blanc that connects France to Italy and is used daily by about 5000 trucks [11].

The valley is surrounded by mountain chains, and segmented by a series of bottlenecks that perturb air circulation. This topography, with the high density of air pollution emission sources (industries, traffic, and woodstoves during winter) in a small area, and the frequency of cold temperature inversions common in the valley during winter, results in an exceedance of air quality target or limit values for several pollutants. $\mathrm{PM}_{10}$ concentrations show a strong seasonal pattern with high concentrations in winter, frequently exceeding $50 \mu \mathrm{g} / \mathrm{m}^{3}$. Since the beginning of $\mathrm{PM}_{10}$ measurements in 1999, the daily limit value $\left(80 \mu \mathrm{g} / \mathrm{m}^{3}\right)$ is exceeded several times each year, with a maximum concentration of $188 \mu \mathrm{g} / \mathrm{m}^{3}$ measured in 2009. The residential sector, mainly wood heating, is the main source of fine particulate matter emissions $\left(70 \%\right.$ of emissions for $\left.\mathrm{PM}_{2.5}\right)$ during winter $[11,12]$. The target value for benzo-a-pyrene ( $1 \mathrm{ng} / \mathrm{m}^{3}$ on annual mean) is also exceeded at the air quality monitoring station, located in the narrowest part of the valley, again with a strong seasonal pattern.

High $\mathrm{NO}_{2}$ annual concentrations (around $40 \mu \mathrm{g} / \mathrm{m}^{3}$ per year) are observed at the vicinity of the main traffic road, which connects the western and eastern parts of the valley. Annual concentrations 
at urban stations range between 20 and $30 \mu \mathrm{g} / \mathrm{m}^{3}$ per year. The Arve Valley is one of the 24 areas in France for which the European Court of Justice has stated that the annual limit value for $\mathrm{NO}_{2}$ has been systematically and persistently exceeded since 2010, and that actions implemented to solve the situation have been insufficient [13]. Finally, during summer, ozone formation is favored by sunshine and altitude.

Figure 2 illustrates the trends in annual mean concentrations of $\mathrm{NO}_{2}, \mathrm{PM}_{10}$, and $\mathrm{PM}_{2.5}$ measured in the valley between 2008 and 2019. Fixed measurements of $\mathrm{PM}_{2.5}$ started in 2016.

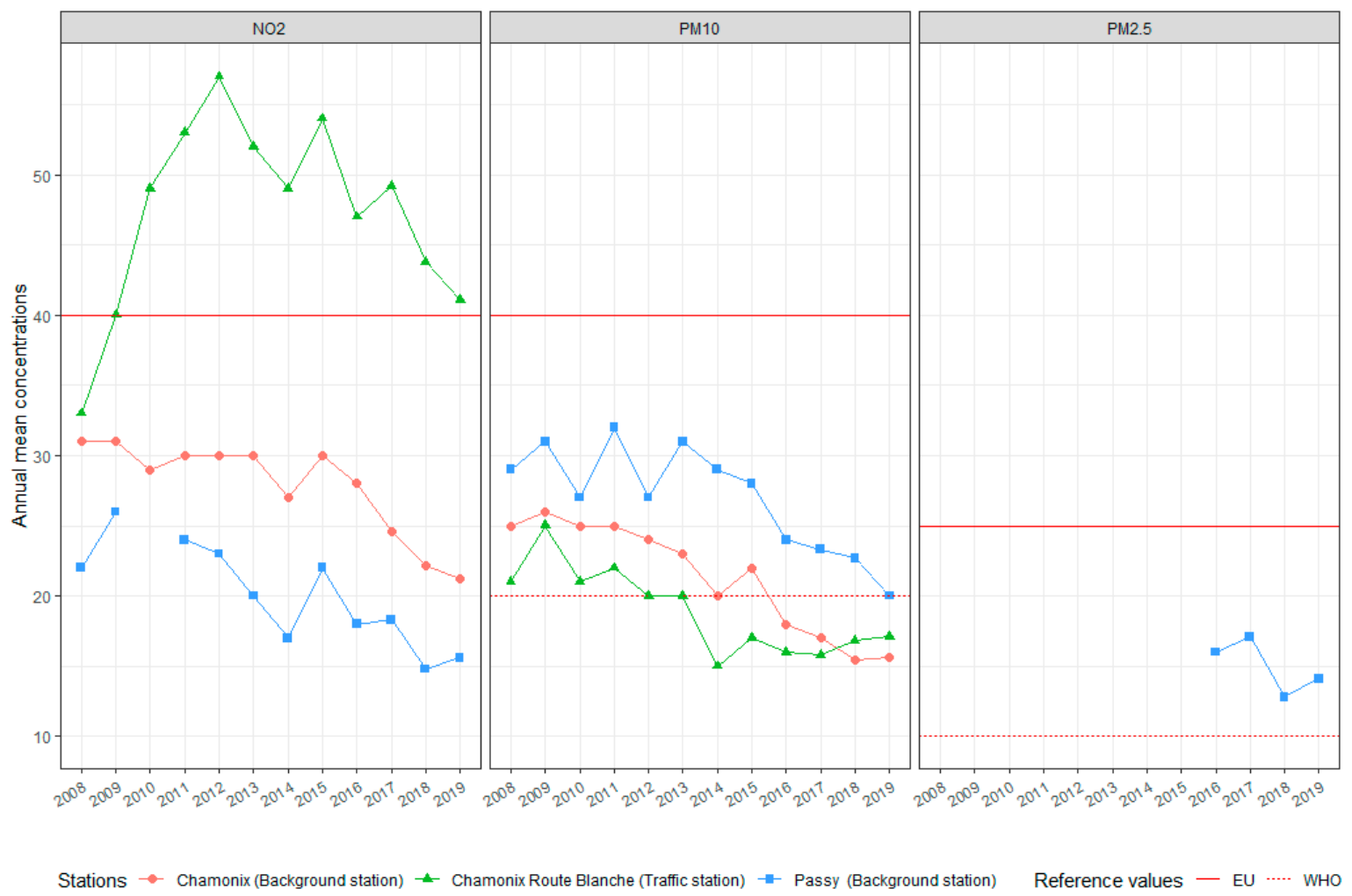

Figure 2. Annual trends in $\mathrm{NO}_{2}, \mathrm{PM}_{10}$, and $\mathrm{PM}_{2.5}$ measured in the valley between 2008 and 2019 (data source: Atmo Auvergne Rhône Alpes).

During winter, the population can perceive air pollution, as the visibility is modified. A qualitative study on the perception of air pollution in the valley found that $40 \%$ of the participants perceived a poor air quality, and $65 \%$ a degradation of the air quality through time. A majority of the study participants linked poor air quality with health issues $[14,15]$. Concerns were especially exacerbated by three episodes during winters 2011, 2013, and 2016, when $\mathrm{PM}_{10}$ concentrations exceeded $50 \mu \mathrm{g} / \mathrm{m}^{3}$ for more than 15 consecutive days. In recent years, several non-governmental associations have been created to claim for a better air quality. In 2015, the debate crystalized around the number of deaths attributable to air pollution in the area. Stakeholders expressed strong, contradictory opinions, and received acute political and media attention including at the national level [16].

Meanwhile, the objectives of the first plan for the protection of the atmosphere (PPA) were to reduce PM emissions by 30\% between 2011 and 2016. One action was the setup in 2013 of a fund to provide financial support to inhabitants who wished to replace old heating devices (older than 2002) or open stoves with a more efficient installation. Similar initiatives were subsequently taken up in other territories. Short movies and educational supports were developed to raise awareness of the negative impacts of wood-burning heaters among the population [17].

Truck traffic was the most frequently identified source of air pollution by the population, while biomass burning was not perceived as a major contributor $[14,15]$. The discrepancy between the 
focus of governmental institutions on biomass burning, and the low perception of its contribution to air pollution by the population has resulted in extensive debate.

In this context, the French public health agency was requested by the local health authorities to document the health impacts of air pollution in the area. However, developing an epidemiological study did not seem justified in that context. The scientific knowledge was sufficient to conclude that air pollution levels in the Arve Valley presented a risk for the population. It would not add any new evidence, while methodological issues, costs, and long delays were expected before obtaining results. The risk would have been to further defer the implementation of actions by the local authorities, given the local controversy on the health impacts of air pollution

A HIA was seen as a better choice, as it gives an opportunity to structure the existing knowledge on air pollution, combining literature-based evidence with local data. It can be performed rapidly, it is transparent, easily reproducible, and can be used to promote a collaborative practical discussion among stakeholders. A quantitative HIA demonstrates the magnitude of the expected health impacts. Outputs of HIAs hopefully lead to the discussion on appropriate interventions/solutions to the identified problem. It helps overcome existing silos and shifts the overriding question from "Is it true that air pollution kills people?" to "What can we do to improve air quality?"

\section{Methods}

We performed a quantitative HIA, following the general principles stated by the WHO and the guidelines developed by the French public health agency. The objectives were to quantify the public health burden of air pollution in the area to support decision-making.

The conceptual framework of the HIA was (1) to define a study period and area, based on the availability of data; (2) to choose pairs of pollutants-health outcome to be included in the HIA; (3) to define scenarios; (4) to assess exposure; (5) to select concentration-responses functions (CRFs) and compute the associated impacts; (6) to analyze uncertainties; and (7) to communicate the results. The impacts were assessed considering counterfactuals scenarios (i.e., considering a change in concentrations, all other things being unchanged). Each of the seven steps required specific methodological choices. Details on the equations we used are described elsewhere [18], and a step-by-step guidance on how to perform this type of HIA is available in French [19]. More general guidance on HIA can be found in Bhatia et. al. [20].

In the following, we focus on how stakeholder involvement contributed to shape the choices of the HIA, and do not extensively detail the scientific method.

\subsection{Stakeholder Involvement}

The French public health agency was in charge of implementing this HIA. Selected stakeholders were invited to discuss the objectives, method, and agenda of the HIA and were chosen to represent a diversity of local interests: air quality, public health, environmental regulation organizations, researchers from a regional university, mayors, and non-governmental associations (NGOs). The French environment and energy management agency was the only national stakeholder involved, as it managed the fund to replace old and open stoves.

The first stakeholder meeting was an opportunity to summarize the current knowledge on air pollution and health, to explain the differences between epidemiological studies and HIA, and to clarify what the HIA would and would not provide. Discussions influenced the choice of the scope of the HIA, the scenarios that were to be tested, and some sensitivity analyses to be added to the initial protocol.

Once the HIA was performed, results were presented to stakeholders before their dissemination to the general population. A final meeting was organized with the Ministries of Environment, Health and Transports, local stakeholders, and the population. Its agenda was to explain the results of the HIA, and to discuss the local concerns and opportunities for action. 


\subsection{Defining the Scope of the Health Impact Assessment (HIA)}

Initially, stakeholders were highly concerned with acute air pollution episodes of $\mathrm{PM}_{10}$ and $\mathrm{NO}_{2}$. During the first meeting, they agreed on the French public health agency proposal of an HIA focusing on the mortality impacts of chronic exposure to fine particles $\left(\mathrm{PM}_{2.5}\right)$.

This scope implies several choices. First, the focus on long-term exposure, rather than on air pollution episodes. Reasons were that (1) acute episodes contribute to long-term exposure, (2) the long-term effects of air pollution largely outweigh the short-term effects, and a focus on acute episodes would underestimate the actual public health burden [21], and (3) actions focusing on the reduction of acute episodes would be less efficient than long-term interventions.

Second, the focus was on $\mathrm{PM}_{2.5}$, while initial concerns were expressed for $\mathrm{PM}_{10}$ and $\mathrm{NO}_{2}$. These pollutants have attracted attention because they were measured in the Valley, and because acute air pollution episodes are identified when $\mathrm{PM}_{10}$ and $\mathrm{NO}_{2}$ daily concentrations reach regulatory thresholds. However, epidemiological and toxicological studies underline the hazardousness of $\mathrm{PM}_{2.5}$, making it a better indicator than $\mathrm{PM}_{10}$ to study the effect of long-term exposure [9].

As for $\mathrm{NO}_{2}$, it was not retained, given that (1) part of the impacts of $\mathrm{NO}_{2}$ would be included in the impacts of $\mathrm{PM}_{2.5}$ [9], and (2) high levels of $\mathrm{NO}_{2}$ were observed in the close vicinity of roads. A total of $0.3 \%$ of the population was exposed to levels higher than the EU regulatory value of $40 \mu \mathrm{g} / \mathrm{m}^{3}, 5 \%$ to levels between 30 and $40 \mu \mathrm{g} / \mathrm{m}^{3}$, and $50 \%$ to levels between 20 and $30 \mu \mathrm{g} / \mathrm{m}^{3}$. HIA are recommended only for $\mathrm{NO}_{2}$ concentrations exceeding $20 \mu \mathrm{g} / \mathrm{m}^{3}$ [9].

It was acknowledged that $\mathrm{NO}_{2}$ concentrations had an impact in the Valley, but that it would not be quantified per se in the HIA.

Finally, the total mortality was chosen as the health end point, considering that (1) the causality and the robustness of the $\mathrm{PM}_{2.5}$-total mortality relationship was consensual in the scientific literature [9], (2) morbidity data would have been of interest, but were not available on a routine basis in the area, and (3) the results could be compared with other French HIAs [18].

The general philosophy was that a HIA "a minima", focusing only on $\mathrm{PM}_{2.5}$ and mortality, was more likely to be accepted by a large number of stakeholders, rather than a HIA covering more impacts and pollutants, but also having more uncertainties.

Additionally, given the lack of monitoring station for $\mathrm{PM}_{2.5}$ in the area, choosing this pollutant implied that air quality modeling would have to be used to assess exposure, with the approach described below.

\subsection{Study Period and Study Area}

The study area consisted of the 41 municipalities of the Valley, also corresponding to the study area of the PPA. The study period was restricted to 2012-2013 due to the availability of mortality data. Population by age was obtained from the National Institute of Statistics and Economic Studies (Insee), on a $200 \times 200 \mathrm{~m}$ grid. Annual total mortality (ICD10 A00-Y98) by age was obtained from the French National Institute of Health and Medical for each municipality. We only considered the population of residents, and did not take tourists into account.

\subsection{Scenarios}

Four scenarios were developed with the local stakeholders:

- "Without anthropogenic pollution", where none of the municipalities would exceed the concentrations observed in the less polluted rural municipalities. The threshold was fixed at the 5th percentile of the $\mathrm{PM}_{2.5}$ annual concentrations considering the whole surface of the municipality (i.e., $4.9 \mu \mathrm{g} / \mathrm{m}^{3}$ ).

- "Decrease by 30\%", where all concentrations would be decreased by $30 \%$.

- "Decrease by 10\%", where all concentrations would be decreased by $10 \%$. 
- "WHO Guidelines scenario", where none of the municipalities would exceed the $\mathrm{PM}_{2.5}$ WHO guideline value of $10 \mu \mathrm{g} / \mathrm{m}^{3}$.

\subsection{Exposure to $P M_{2.5}$}

In this kind of approach, it is not possible to estimate the individual exposure of any inhabitants in the area. However, the objective was to match as much as possible with the method that was used to assess exposure in the epidemiological studies providing the concentration-response functions, detailed later on. One of the epidemiological studies we selected characterized exposure at the municipality level based on a fine-scale air quality model [22,23]. Given that deterministic models were already available and used locally to support decision-making, we favored that option. We tried to adopt a comparable approach to assess exposure in the Arve Valley. An alternative would have been to assess exposure through a land use regression model $[24,25]$.

$\mathrm{PM}_{2.5}$ annual concentrations were modeled over the area for 2012 and 2013 by Atmo Auvergne-Rhône-Alpes. The fine-scale regional emission inventory maintained by the local air quality monitoring network provided the entry data. A nested-modeling chain was used, combining the weather research and forecasting model (WRF), the air quality CHIMERE model [26], and a geostatistical treatment to provide a first estimation of the PM concentrations. It was completed by the fine-scale dispersion model Sirane to obtain estimates on a $10 \times 10 \mathrm{~m}$ grid $[27,28]$.

Concentrations were aggregated to compute an annual exposure concentration at the municipality level.

Stakeholders were concerned that this aggregation would lead to under or over-estimation of the actual exposure. Three alternative approaches were tested:

- "Whole area" approach: average of gridded-concentrations, weighted by the surface covered by each cell overlapping with the municipality.

- "Inhabited areas" approach: average of gridded-concentrations, weighted by the surface excluding cells overlapping with natural spaces based on the $200 \mathrm{~m}$ resident's location data.

- "Population-weighted" approach: average of gridded-concentrations, weighted by the surface excluding cells overlapping with natural spaces based on the $200 \mathrm{~m}$ resident's location data, and weighted by the population of the corresponding cell.

Under the "whole area" approach, the hypothesis is that on average, the population residing in a municipality spends time, and is thus exposed, to all areas of the municipalities including natural areas. Under the other approaches, the hypothesis is that the population stays in the artificial areas of the municipalities, especially in the most populated areas.

\subsection{Choice of the Concentration-Response Function}

In an HIA, the concentration-response function (CRF) is used to translate changes in air pollutant concentrations into changes in the studied health outcome rate. CRF were selected from the international peer-reviewed literature. In this study, we reviewed European cohort studies estimating the chronic impacts of $\mathrm{PM}_{2.5}$ on total mortality $[6,23,24,29,30]$. Studies involving French participants were favored to limit possible biases linked with the geographical transposition of the CRF. Based on the results of two studies, the French cohort Gazel-air [23] and the European Study of Cohorts for Air Pollution Effects Escape [6], we derived a CRF for France, following a method described elsewhere [18]. This CRF, expressed as a relative risk (RR) of mortality, was $1.15\left(95 \%\right.$ CI 1.05-1.25) for a $10 \mu \mathrm{g} / \mathrm{m}^{3}$ increase in $\mathrm{PM}_{2.5}$ (i.e., mortality increases by $15 \%$ when $\mathrm{PM}_{2.5}$ increased by $10 \mu \mathrm{g} / \mathrm{m}^{3}$ ). Consistently with the studies providing the $C R F$, we considered a log-linear relationship between mortality and $\mathrm{PM}_{2.5}$.

Alternative CRFs were included in the sensitivity analysis: one recommended by the World Health Organization (WHO) [9] to facilitate the comparison with international studies, and two derived from European studies including those without French participants [18]. 


\subsection{Health Impact Equations}

The CRF and local data were combined to assess the impacts of $\mathrm{PM}_{2.5}$ on mortality in each municipality using classical HIA equations detailed elsewhere $[18,21]$. The general principle is to compare the fraction of mortality attributable to the current exposure to $\mathrm{PM}_{2.5}$, and the one attributable under the counterfactual (scenarios) exposures. The CRFs provide the mathematical information to compute those attributable fractions.

All the computations were made considering that a decrease in air pollution concentrations would immediately result in a decrease in mortality. No lag was taken into account between the air quality improvement and the health benefits.

Results were expressed in terms of number of avoidable deaths per year, and in terms of gain in life expectancy. The $95 \%$ confidence interval of the CRF was used to compute a confidence interval surrounding the HIA results, even though it only represents the uncertainty resulting from the statistical uncertainty, and thus does not take into account other sources of uncertainties propagated to HIA results.

\section{Results}

\subsection{Main Characteristics of the Study Area}

\subsubsection{Population and Mortality}

The 41 municipalities of the area gathered 154,718 inhabitants in 2012-2013 with an average all-cause mortality rate (for people aged 30 and over) of 1030 deaths per 100,000 inhabitants. Life expectancy at 30 was estimated to be on average 53 years (Table 1).

Table 1. Characteristics of the study area.

\begin{tabular}{ccc}
\hline Characteristics & Value & Source \\
\hline Number of municipalities & 41 & Plan de protection de l'atmosphère \\
Total area & $1224 \mathrm{~km}^{2}$ & Insee (2013) \\
Area classified as natural space & $1016 \mathrm{~km}^{2}$ & Insee (2013) \\
Population & 154,718 inhabitants & Insee (2012-2013) \\
Population aged 30 years and over & 97,937 inhabitants & Insee (2012-2013) \\
All-cause mortality rate (30 years and over) & 1030 deaths per 100,000 & CépiDC (2012-2013) \\
Life expectancy at 30 & inhabitants & Average for all municipalities (2012-2013) \\
\hline
\end{tabular}

\subsubsection{Exposure Assessment}

Annual $\mathrm{PM}_{2.5}$ concentrations ranged from 4.9 to $14 \mu \mathrm{g} / \mathrm{m}^{3}$ using the "inhabited areas" approach. A total of $68 \%$ of the population was exposed to annual concentrations exceeding $10 \mu \mathrm{g} / \mathrm{m}^{3}$. Exposures assessed by the "inhabited areas" and by the "population-weighted" approaches were on average quite similar. Lower estimates were found in the "whole-area" approach: based on this method, only $57 \%$ of the population was exposed to annual concentrations exceeding $10 \mu \mathrm{g} / \mathrm{m}^{3}$.

While stakeholders express concerns of a worsened air quality in the eastern part of the Valley (possibly due to the location of the air monitoring station in Passy and Chamonix, the vicinity of the Mont Blanc Tunnel), the results showed higher concentrations in the western part of the Valley (Figure 3). 


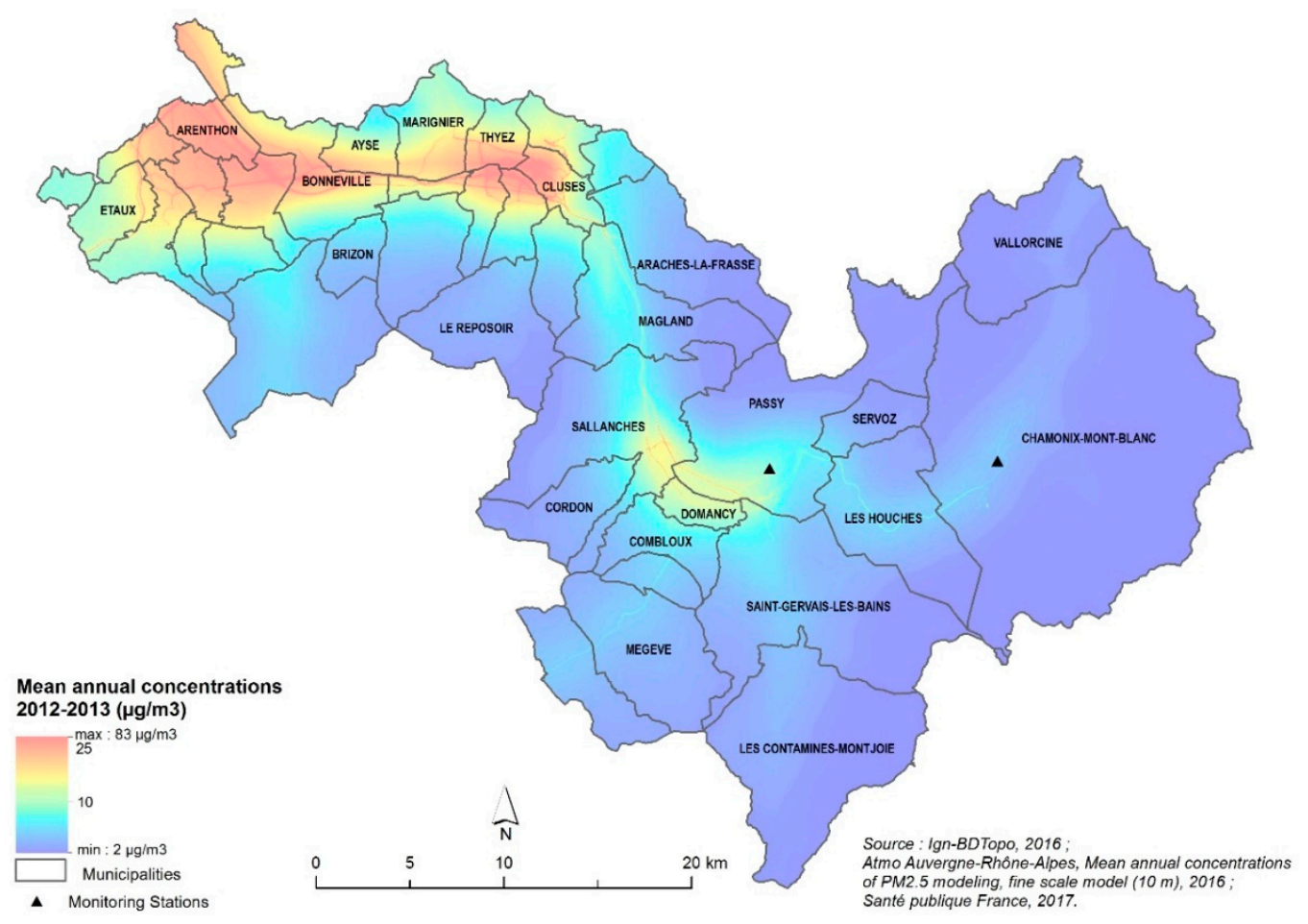

Figure 3. $\mathrm{PM}_{2.5}$ annual mean concentration, on a $10 \times 10 \mathrm{~m}$ grid.

\subsection{Mortality Impacts of Chronic Exposure to $P M_{2.5}$}

It was agreed that the main results were based on the "inhabited areas" approach and using a RR of 1.15 [95\% Confidence Interval (CI) 1.05:1.25] for a $10 \mu \mathrm{g} / \mathrm{m}^{3}$ increase in $\mathrm{PM}_{2.5}$. Alternative combinations of exposure assessment approaches and RR were presented as sensitivity analyses.

The HIA estimated that chronic exposure to $\mathrm{PM}_{2.5}$ contributed to $8 \%$ of the annual mortality in the study area under the "without anthropogenic pollution scenario". This represents 85 [95\%CI 31:131] deaths per year; 1931 years of life lost \{95\%CI 670:3104], and on median nine [95\%CI 3:15] months of life expectancy lost for people aged 30.

A 30\% decrease in the annual $\mathrm{PM}_{2.5}$ concentrations in each municipality would result in a $4 \%$ decrease in total mortality, representing 45 (16:70) deaths per year, 967 [95\%CI337:1548] years of life saved, and on average, a life expectancy at 30 increased by five months [95\%CI 2:8]. The gain in life expectancy would be higher in the western part of the Valley (Figure 4).

A 10\% decrease would save 15 [95\%CI 5:24] deaths and 321 [95\%CI 112:514] years of life per year. Compliance with the WHO guideline values of $10 \mu \mathrm{g} / \mathrm{m}^{3}$ in all municipalities of the area would save 21 [95\% CI 7:33] premature deaths (i.e., 492 [95\%CI 172:788] years of life per year). 


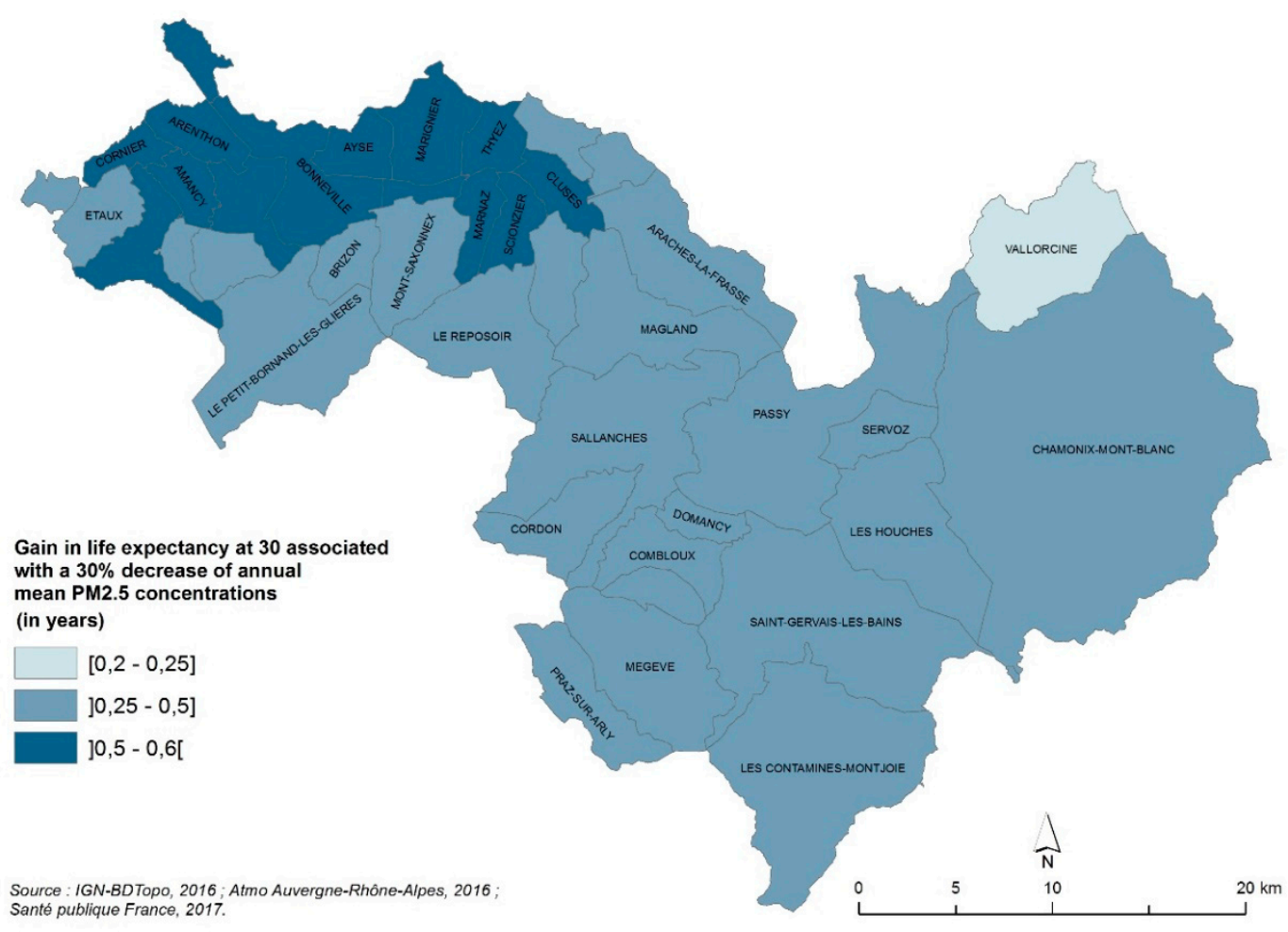

Figure 4. Gain in life expectancy at 30 (years) associated with a 30\% decrease in annual mean $\mathrm{PM}_{2.5}$ concentrations.

\subsection{Sensitivity Analyses}

A summary of the sensitivity analysis is presented in Figure 5. It shows that the choice of the RR, as expected, had a major influence on the results, changing the estimated number of deaths attributable to anthropogenic $\mathrm{PM}_{2.5}$ by a factor up to four. In contrast, the exposure assessment approach modified the results by a factor up 1.8, comparing the population-weighted approach vs. the whole area approach. This is important information for stakeholders, as it illustrates that further refining air quality models and exposure assessment would not drastically modify the order of magnitude of the health impacts.

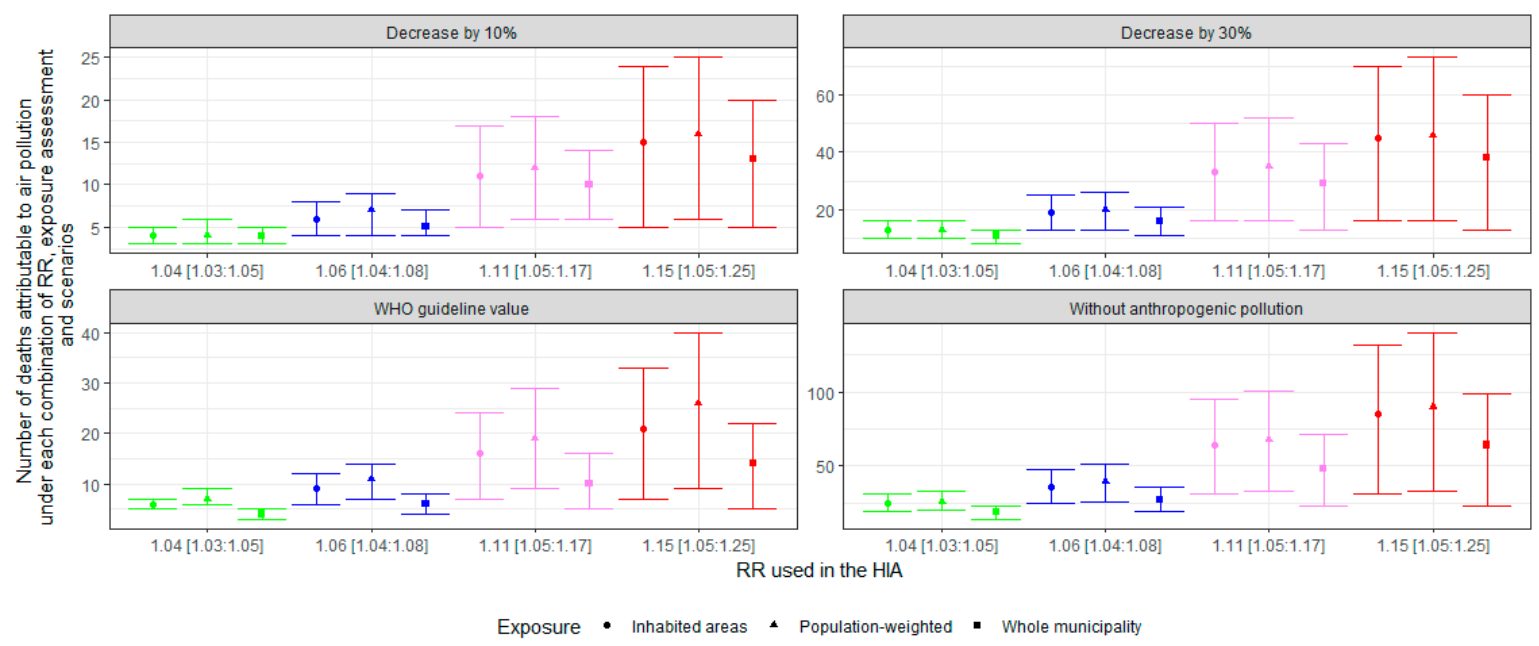

Figure 5. Central estimates (95\% CI) of mortality impacts under the different scenarios by relative risk and by the exposure assessment approach. 


\subsection{Communication of Results}

HIA results were made available to all stakeholders and the general population via a comprehensive scientific report and a summary report [31]. Specific attention was given to help decision-makers understand the HIA approach, and the meaning of the findings. Local health and environmental authorities had a key role to play in the dissemination of the results. A comprehensive Frequently Asked Questions was developed jointly with and for the local public health agency and the air monitoring association to ensure a shared understanding of all the aspects of the HIA. Transparency on the choices made at each step of the HIA (RRs, scenarios, exposure assessment) supported this process.

\section{Discussion}

\subsection{Summary and Relevance of the HIA Results in the Local Context}

The HIA based on a fine-scale air quality model estimated that $8 \%$ of the mortality was attributable to chronic exposure to $\mathrm{PM}_{2.5}$ in the Arve Valley. These results can be compared with the French nationwide estimate for which on average $\mathrm{PM}_{2.5}$ contributed to $9 \%$ of the mortality, $8 \%$ in urban areas between 20,000 and 100,000 inhabitants, and 13\% in urban areas larger than 100,000 inhabitants [32]. At least $68 \%$ of the population of the Arve Valley was exposed to annual concentrations exceeding the WHO guideline value. Compliance with this value could reduce the annual mortality by $2 \%$, again close to the nationwide estimate (3\%) [32].

The main key messages for stakeholders were that the findings of this HIA provided a minimum indication of the impact of air pollution and of the achievable benefits. This is associated with limits and uncertainties, and does not take into account all the pollutants, nor the wide range of possible health benefits, in terms of avoided specific mortality and morbidity.

Considering the high population density at the bottom of the valley, and the concentration of human activities in a small space, it can be assimilated to an urban area, despite the presence of inhabited natural spaces. Exposure and associated impacts were similar to those estimated for urban areas of the same size, and lower than those estimated for urban areas above 100,000 inhabitants [18], and the public health impact was large, with 85 deaths per year due to $\mathrm{PM}_{2.5}$.

\subsection{Limits and Uncertainties}

Discussion of the limits and uncertainties of our HIA was an important aspect of the interactions with stakeholders. The topography and the weather conditions make air quality modeling in the Arve Valley complicated. In addition, the absence of fixed monitoring stations for $\mathrm{PM}_{2.5}$ before 2015 limits the possibility of calibrating the model for our study period. The 2016 annual $\mathrm{PM}_{2.5}$ mean measured at Passy Station was $16.1 \mu \mathrm{g} / \mathrm{m}^{3}$. The concentration estimated by the model for 2012-2013 for the municipality of Passy was $6.4 \mu \mathrm{g} / \mathrm{m}^{3}$ under the "whole area" approach and $9.7 \mu \mathrm{g} / \mathrm{m}^{3}$ under the "inhabited areas" approach. These data are not directly comparable (concentration measured at one point vs modeled over a municipality, and for different years), but still suggest that modeled concentrations are under-estimated compared to measurements. In addition, a work based on more precise modeling data 2016-2017-2018 found that the geographical spread of air pollution may be different than the one modeled for 2012-2013, with higher concentrations in the central sector of Passy-Sallanches [33]. Developing the monitoring of $\mathrm{PM}_{2.5}$ in the area is an asset to reduce the uncertainties of future HIA.

The sensitivity analyses underlined the importance of the choice of the CRF in an HIA. However, a source of uncertainty not taken into account in the analysis lies in the possibility of transposing the CRF to a semi-urban background, where residential wood burning is the main PM source. However, two reviews of the toxicological and epidemiological data on wood smoke concluded that there was no indication that the effects of PM in areas polluted by wood smoke were weaker than in other areas $[34,35]$. Naeher et al. considered that there was no evidence of significant differences with other combustion-derived particles of the same size range regarding respiratory health, and that the 
evidence was too limited regarding cardiovascular health and cancer [34]. In a more recent analysis, WHO underlined the growing evidence on cardiovascular health, but also the lack of studies specifically focusing on indicators of wood combustion [36].

\subsection{Integration of the HIA in the PPA}

One of the biggest contributions of this HIA was that the debate on the reality of air pollution-related health impacts in the valley was reduced, and a new discussion arose on choices for actions to reduce air pollution.

It contributed to the discussion surrounding a new PPA, to be implemented in 2019-2023. This new plan was developed by stakeholders and approved in April 2019. It lists 30 actions targeting all emission sources, but also governance and communication. For example, one action is to create a broad network of air "ambassadors" throughout the entire region, because the challenge lies in changing the behavior and perceptions of what pollutes more in the region (in particular wood heating, which is perceived positively in people's minds).

Meetings organized to share our HIA with all the stakeholders were also an opportunity for them to exchange their views and understanding of the situation and each other better. For instance, during the HIA process, differences between emissions and concentrations were discussed and explained. In the new PPA, environmental objectives are now expressed in terms of concentrations, rather than in terms of emissions as in the previous plan. Specifically, the 30\% decrease scenario used in the HIA was adopted in the new PPA. It also encompasses two additional objectives targeting public health: (1) a $50 \%$ reduction of the mortality attributable to air pollution in the Valley in 2023; (2) five months of life expectancy gained in 2023.

Air pollution is still a controversial issue in the area, with the debates concentrating on the contribution of the different sources. Concerns about the health impacts of other air pollutants (e.g., polyaromatic hydrocarbons) are still high. Several inhabitants of the valley lodged a complaint against $X$ and against the French government. In December 2019, the local government decided to forbid open wood-stoves in all municipalities in the area by 2022.

\section{Conclusions}

The study in the Arve Valley illustrates how HIA can be concretely used to promote dialogue and actions at the local level. We estimate that the technical part of the process (data collection, protocol, analysis) accounted for about $25 \%$ of the resources allocated to the project, while $75 \%$ was used for communication with stakeholders, and translation of the scientific methods and findings for non-scientists.

This HIA showed, once again, that a collaborative approach is essential to ensure that the health consequences of air pollution are taken into account in the planning of emissions reduction actions, but is not sufficient to act. This must be followed by work to identify the main emission sources and possible solutions.

Our HIA showed the impact on mortality, which represents only part of the health effects. We are aware that this impact may be insufficient to raise enough awareness. Stakeholders and the general population could be more sensitive to findings on the effects of air pollution on the development or aggravation of diseases, on the quality of life, and particularly on the health of children. Our efforts will now focus on including morbidity outcomes in future HIAs. 
Author Contributions: Conceptualization, M.P., P.D.C.-C., and J.-M.Y.; Methodology, M.P. and J.-M.Y; Analysis, M.P.; Data curation, M.C and P.D.C.-C.; Writing-original draft preparation-review, M.P., Writing-review and editing M.P.; M.C., J.-M.Y., M.B., and S.M.; Supervision, S.M. All authors have read and agreed to the published version of the manuscript.

Funding: This research received no external funding.

Acknowledgments: We thank Atmo Auvergne Rhône-Alpes, the local public health agency, and all the stakeholders contributing to the follow-up of the HIA.

Conflicts of Interest: The authors declare no conflicts of interest.

\section{References}

1. Hoek, G.; Krishnan, R.M.; Beelen, R.; Peters, A.; Ostro, B.; Brunekreef, B.; Kaufman, J.D. Long-term air pollution exposure and cardio- respiratory mortality: A review. Environ. Health 2013, 12, 43. [PubMed]

2. Pope, C.A.; Burnett, R.T.; Thurston, G.D.; Thun, M.J.; Calle, E.E.; Krewski, D.; Godleski, J.J. Cardiovascular Mortality and Long-Term Exposure to Particulate Air Pollution: Epidemiological Evidence of General Pathophysiological Pathways of Disease. Circulation 2004, 109, 71-77. [CrossRef] [PubMed]

3. Brook, R.D.; Rajagopalan, S.; Pope, C.A.; Brook, J.R.; Bhatnagar, A.; Diez-Roux, A.V.; Holguin, F.; Hong, Y.; Luepker, R.V.; Mittleman, M.A.; et al. Particulate matter air pollution and cardiovascular disease: An update to the scientific statement from the american heart association. Circulation 2010, 121, 2331-2378. [CrossRef] [PubMed]

4. Hoek, G.; Raaschou-Nielsen, O. Impact of fine particles in ambient air on lung cancer. Chin. J. Cancer 2014, 33, 197-203. [PubMed]

5. Centre International de Recherche sur le Cancer. Les Gaz D'échappement des Moteurs Diesel Cancérogènes; Organisation Mondiale de la Santé: Lyon, France, 2012; pp. 1-3.

6. Beelen, R.; Raaschou-Nielsen, O.; Stafoggia, M.; Andersen, Z.J.; Weinmayr, G.; Hoffmann, B.; Wolf, K.; Samoli, E.; Fischer, P.; Nieuwenhuijsen, M.; et al. Effects of long-term exposure to air pollution on natural-cause mortality: An analysis of 22 European cohorts within the multicentre ESCAPE project. Lancet 2014, 383, 785-795. [PubMed]

7. Pope, C.A.; Dockery, D.W. Health effects of fine particulate air pollution: Lines that connect. J. Air Waste Manag. Assoc. 2006, 56, 709-742. [CrossRef]

8. WHO. Review of Evidence on Health Aspectes of Air Pollution-Revihaap Project; World Health Organisation: Copenhague, Danemark, 2013; pp. 1-309.

9. WHO. Health Risks of Air Pollution in Europe-Hrapie Project-Recommandations for Concentration-Response Functions for Cost-Benefits Analysis of Particulate Matter, Ozone and Nitrogen Dioxide; WHO Regional Office for Europe: Copenhague, Danemark, 2013; pp. 1-60.

10. Medina, S.; Ballester, F.; Chanel, O.; Declercq, C.; Pascal, M. Quantifying the health impacts of outdoor air pollution: Useful estimations for public health action. J. Epidemiol. Community Health 2013, 67, 480-483.

11. Préfecture-de-Haute-Savoie. Plan. de Protection de L'atmosphère de la Vallée de l'Arve; Préfecture-de-Haute-Savoie: Annecy, France, 2012; pp. 1-69.

12. Bonvalot, L.; Tuna, T.; Fagault, Y.; Jaffrezo, J.L.; Jacob, V.; Chevrier, F.; Bard, E. Estimating contributions from biomass burning, fossil fuel combustion, and biogenic carbon to carbonaceous aerosols in the Valley of Chamonix: A dual approach based on radiocarbon and levoglucosan. Atmos. Chem. Phys. 2016, 16, 13753-13772. [CrossRef]

13. Judgment of the Court (Seventh Chamber) of 24 October 20196 European Commission v French Republic-Case C-636/18; Court of justice of the European Union: Luxembourg, 2019.

14. Roussel, I. Dans la vallée de l'Arve, une approche innovante de la gestion de la pollution atmosphérique. Pollut. Atmos. 2017, 231-232.

15. Préfecture-de-Haute-Savoie. Enquête Publique-Plan de Protection de L'atmosphère (Projet); Préfecture de Haute Savoie: Annecy, France, 2011; pp. 1-399.

16. Cassagne, E.P.; Martin, S.; Ségala, C. Suivi du Changement D'équipements et de L'évolution des Pratiques Liées à la Combustion de Biomasse Dans le Cadre de la Prime Air Bois de la Vallée de l'Arve; Agence de la transition écologique: Montrouge, France, 2018; pp. 1-110. 
17. SM3A. Le SM3A et la politique de l'air-Le fond air bois. Available online: http://www.riviere-arve.org/ projets/fonds-chaleur-air-bois.htm (accessed on 2 March 2020).

18. Pascal, M.; de Crouy Chanel, P.; Wagner, V.; Corso, M.; Tillier, C.; Bentayeb, M.; Blanchard, M.; Cochet, A.; Pascal, L.; Host, S.; et al. The mortality impacts of fine particles in France. Sci. Total Environ. 2016, 571, 416-425. [CrossRef]

19. Pascal, M.; Yvon, J.-M.; Medina, S. Pollution Atmosphérique. Guide Pour la Réalisation D'une Évaluation Quantitative des Impacts sur la Santé (EQIS). EQIS Avec une Exposition Modélisée; Santé Publique France: Saint-Maurice, Switzerland, 2019; p. 92.

20. Bhatia, R. Health Impact Assessment, a Guide for Practice; Human Impact Partners: Oakland, CA, USA, 2011; pp. 1-89.

21. Pascal, M.; Corso, M.; Chanel, O.; Declercq, C.; Badaloni, C.; Cesaroni, G.; Henschel, S.; Meister, K.; Haluza, D.; Martin-Olmedo, P.; et al. Assessing the public health impacts of urban air pollution in 25 European cities: Results of the Aphekom project. Sci. Total Environ. 2013, 449, 390-400. [CrossRef] [PubMed]

22. Bentayeb, M.; Stempfelet, M.; Wagner, V.; Zins, M.; Bonenfant, S.; Songeur, C.; Sanchez, O.; Rosso, A.; Brulfert, G.; Rios, I.; et al. Retrospective modeling outdoor air pollution at a fine spatial scale in France, 1989-2008. Atmos. Environ. 2014, 92, 267-279. [CrossRef]

23. Bentayeb, M.; Wagner, V.; Stempfelet, M.; Zins, M.; Goldberg, M.; Pascal, M.; Larrieu, S.; Beaudeau, P.; Cassadou, S.; Eilstein, D.; et al. Association between long-term exposure to air pollution and mortality in France: A 25-year follow-up study. Environ. Int. 2015, 85, 5-14. [CrossRef]

24. Beelen, R.; Stafoggia, M.; Raaschou-Nielsen, O.; Andersen, Z.J.; Xun, W.W.; Katsouyanni, K.; Dimakopoulou, K.; Brunekreef, B.; Weinmayr, G.; Hoffmann, B.; et al. Long-term Exposure to Air Pollution and Cardiovascular Mortality: An Analysis of 22 European Cohorts. Epidemiology 2014, 25, 368-378. [CrossRef] [PubMed]

25. de Hoogh, K.; Wang, M.; Adam, M.; Badaloni, C.; Beelen, R.; Birk, M.; Cesaroni, G.; Cirach, M.; Declercq, C.; Dedele, A.; et al. Development of land use regression models for particle composition in twenty study areas in Europe. Environ. Sci. Technol. 2013, 47, 5778-5786. [CrossRef] [PubMed]

26. Terrenoire, E.; Bessagnet, B.; Rouil, L.; Tognet, F.; Pirovano, G.; Létinois, L.; Beauchamp, M.; Colette, A.; Thunis, P.; Amann, M.; et al. High-resolution air quality simulation over Europe with the chemistry transport model CHIMERE. Geosci. Model. Dev. 2015, 8, 21-42. [CrossRef]

27. Soulhac, L.; Salizzoni, P.; Mejean, P.; Didier, D.; Rios, I. The model SIRANE for atmospheric urban pollutant dispersion; PART II, validation of the model on a real case study. Atmos. Environ. 2012, 49, 320-337. [CrossRef]

28. Soulhac, L.; Salizzoni, P.; Cierco, F.X.; Perkins, R. The model SIRANE for atmospheric urban pollutant dispersion; part I, presentation of the model. Atmos. Environ. 2011, 45, 7379-7395. [CrossRef]

29. Carey, I.M.; Atkinson, R.W.; Kent, A.J.; Van Staa, T.; Cook, D.G.; Anderson, H.R. Mortality associations with long-term exposure to outdoor air pollution in a national English cohort. Am. J. Respir. Crit. Care Med. 2013, 187, 1226-1233. [CrossRef]

30. Cesaroni, G.; Badaloni, C.; Gariazzo, C.; Stafoggia, M.; Sozzi, R.; Davoli, M.; Forastiere, F. Long-term exposure to urban air pollution and mortality in a cohort of more than a million adults in Rome. Environ. Health Perspect. 2013, 121, 324-331. [CrossRef]

31. Pascal, M.; de Crouy Chanel, P.; Wagner, V.; Yvon, J.M.; Saura, C. Impact de L'exposition Chronique aux Particules Fines sur la Mortalité Dans la Vallée de L'ARVE; Santé Publique France: Saint-Maurice, Switzerland, 2017; p. 41.

32. Pascal, M.; De Crouy Chanel, P.; Corso, M.; Medina, S.; Wagner, V.; Goria, S.; Beaudeau, P.; Bentayeb, M.; Le Tertre, A.; Ung, A.; et al. Impacts de L'exposition Chronique aux Particules Fines sur la Mortalité, en France Continentale et Analyse des Gains en Santé, de Plusieurs Scénarii de Réduction de la Pollution Atmosphérique; Santé Publique France: Saint-Maurice, Switzerland, 2016; pp. 1-161.

33. Atmo-Air-Rhône-Alpes. Indicateurs Air Santé: Identification des Points de Cumul de Facteurs de Défaveur Environnementaux, Socio-Économiques et Sanitaires; Atmo-Air-Rhône-Alpes: Lyon, France, 2019; pp. 1-14.

34. Naeher, L.P.; Brauer, M.; Lipsett, M.; Zelikoff, J.T.; Simpson, C.D.; Koenig, J.Q.; Smith, K.R. Woodsmoke health effects: A review. Inhal. Toxicol. 2007, 19, 67-106. [CrossRef] [PubMed] 
35. Boman, B.C.; Forsberg, A.B.; Järvholm, B.G. Adverse health effects from ambient air pollution in relation to residential wood combustion in modern society. Scand. J. Work Environ. Health 2003, 29, 251-260. [CrossRef] [PubMed]

36. Organisation Mondiale de la Sant. Review of Evidence on Health Aspects of Air Pollution-Revihaap Project Technical Report; Organisation Mondiale de la Sant: Copenhague, Danemark, 2013; pp. 1-302.

(C) 2020 by the authors. Licensee MDPI, Basel, Switzerland. This article is an open access article distributed under the terms and conditions of the Creative Commons Attribution (CC BY) license (http://creativecommons.org/licenses/by/4.0/). 